\title{
EPR spin trapping of superoxide from nitric oxide synthase
}

\author{
J. Vásquez-Vivar ${ }^{1,2 *}$, J. Joseph ${ }^{2}$, H. Karoui ${ }^{3}$, H. Zhang ${ }^{2}$, J. Miller ${ }^{1}$, P. Martásek ${ }^{4}$ \\ ${ }^{1}$ Department of Pathology and ${ }^{2}$ Biophysics Research Institute, Medical College of Wisconsin, Milwaukee, WI 53226 USA \\ ${ }^{3}$ University of Provence, 13397 Marseille, Cedex 20, France \\ ${ }^{4}$ University of Texas Health Science Center, San Antonio, TX 78284 USA \\ * Corresponding author: jvvivar@mcw.edu
}

\begin{abstract}
Superoxide formation from nitric oxide synthase has not been thoroughly investigated because of the lack of specific, sensitive and artifact-free methodologies for detecting superoxide. EPR spin trapping is the only specific method for detecting superoxide in biological systems. The development of new superoxide spin traps such as 5-(diethoxyphosphoryl)-5- methyl-pyrroline N-oxide (DEPMPO) 2-ethoxycarbonyl-2-methyl3,4-dihydro-2H-pyrrole-1-oxide (EMPO) and the $\left[{ }^{15} \mathrm{~N}\right]-$ EMPO has significantly improved the sensitivity of superoxide detection by electron paramagnetic resonance (EPR). Unlike 5,5-dimethyl-1pyrroline $\mathrm{N}$-oxide (DMPO), a commonly used superoxide spin trap, both DEPMPO and EMPO form superoxide adducts that are persistent, which do not decay to the corresponding hydroxyl adduct. Using these new spin traps, the EPR-detection of superoxide is now straightforward and more sensitive. These new superoxide traps in combination with the loop gap resonator technology have enabled us to demonstrate unequivocally the formation of superoxide from the endothelial and neuronal isoforms of nitric oxide synthase. Superoxide is formed at the oxygenase domain of the enzyme by a calcium/ calmodulin dependent mechanism. The effect of tetrahydrobiopterin cofactor and NOS inhibitors on the release of superoxide is discussed.
\end{abstract}

\section{Introduction}

Increased formation of superoxide has been implicated in the pathophysiology of several cardiovascular and neurodegenerative diseases $[1,2]$. The exact mechanism(s) by which superoxide mediates its cytotoxic effects are not clear yet, however, evidence indicates that formation of superoxidederived oxidants may be involved $[3,4,5]$. Superoxide generates other biological oxidants such as hydrogen peroxide by dismutation $\left(k \approx 10^{5} \mathrm{M}^{-1} \mathrm{~s}^{-1}\right)[6]$, and peroxynitrite from the reaction with nitric oxide $\left({ }^{\circ} \mathrm{NO}\right)\left(k \approx 10^{9} \mathrm{M}^{-1} \mathrm{~s}^{-1}\right)$ [7]. Another biologically relevant reaction of superoxide is with iron-sulfur-containing proteins such as aconitase, which is readily inactivated by superoxide $\left(k=10^{7} \mathrm{M}^{-1} \mathrm{~s}^{-1}\right)$ [8]. Recently, we demonstrated that superoxide releases iron (II) from the $[4 \mathrm{Fe}-4 \mathrm{~S}]^{2+}$ cluster of mitochondrial aconitase that catalyzes the formation of hydroxyl radical $\left({ }^{\circ} \mathrm{OH}\right)$ by a Fenton mechanism [9]. Inactivation of $\mathrm{m}$-aconitase by superoxide is reversible $[9,10]$ which suggests that this mechanism is operative in mitochondrial damage. The extent of the damage is likely to depend on the balance between the rates of superoxide formation and antioxidants defense levels.

Mitochondria are the major source of superoxide in the cell under physiological conditions. It has been estimated that approximately 1-2\% of the total oxygen uptake is partially reduced to generate either superoxide or hydrogen peroxide [11]. Other sources of superoxide include xanthine oxidase and NADPH oxidase that cause an acute elevation of superoxide formation in the extracellular compartment [12]. Superoxide concentrations can be enhanced several times by a redox cycling mechanism from several xenobiotics [13] and metal complexes [14]. Such processes have been implicated in the toxicological mechanism of quinone drugs. More recently, the enzyme nitric oxide synthase (NOS) has been proposed as an intracellular source of superoxide under pathological conditions [15].

\section{Detection of superoxide from NOS}

The detection of superoxide in biological systems is difficult because of the redox properties and low steady state concentrations reached by the radical under physiologically relevant conditions. Most methods currently available for detecting superoxide are indirect and prone to artifacts. Superoxide is a reducing agent $\left(\mathrm{E}^{\prime 0}\left(\mathrm{O}_{2} / \mathrm{O}_{2}^{--}\right) \approx-0.3 \mathrm{~V}\right)$ [16] that displays a relatively low reactivity compared to hydroxyl radical, another oxygen-centered free radical species. One of the most reliable assays for detecting superoxide is the reduction of ferricytochrome c [17]. This method quantifies superoxide by using the fraction of ferricytochrome $\mathrm{c}$ that is inhibited by the superoxide dismutase (SOD). However, flavin-containing proteins like NOS $[18,19]$ and reducing compounds such as tetrahydrobiopterin $\left(\mathrm{BH}_{4}\right)$, an essential cofactor of NOS, directly reduce ferricytochrome c by a mechanism that is SOD-insensitive [20]. 
Another assay to detect superoxide uses nitro blue tetrazolium (NBT) that is reduced to generate monoformazan, which is detected by spectrophotometry. However, both diaphorases and NOS also reduce NBT to generate monoformazan. Moreover, we recently demonstrated that reduction of NBT by NOS enhances the formation of superoxide by a redox-cycling mechanism [21]. This indicates that NBT cannot be used to detected superoxide in biological systems. We demonstrated a similar artifact for other chemiluminescent-based reagents used to detect superoxide. Several chemiluminescent probes have become very popular due to their high sensitivity. Lucigenin, an acridine-based compound, belongs to this class of superoxide detector. The mechanism of the reaction between lucigenin and superoxide is not fully understood. The key step of the chemiluminescent reaction involves the reaction between superoxide and the one-electron reduced intermediate of lucigenin, the lucigenin cation radical [22]. This reaction results in the formation of an electronically excited dioxetane species that decomposes emitting light [23]. How lucigenin cation radical is generated in cellular systems has not been clarified. We have demonstrated that NOS-mediated redox cycling of the lucigenin enhances the generation of superoxide [24]. This suggests that NOS is able to catalyze the formation of lucigenin cation radical [24]. By this mechanism lucigenin catalytically enhances the reduction of oxygen by NADPH at rates that will be dependent on the steady state concentration of lucigenin cation radical. This observation proves that lucigenin cannot be used as a probe for superoxide, as itself generates superoxide. Other methodologies to detect superoxide include: coelenterazine chemiluminescence, which is a redox-inert probe [25] and dihydroethidine fluorescence, which forms ethidium as a red-fluorescent derivate that intercales DNA [26]. The drawbacks of these methods are that the exact mechanism of reaction between superoxide and coelenterazine or hydroethidine is not known and other oxidants could interfere with these assays.

Electron paramagnetic resonance (EPR) measures the absorption of energy by unpaired electron(s) of the free radical species in the presence of a magnetic field. However, free radicals are short-lived species that decay very fast at room temperature. Spin trapping is an auxiliary kinetic technique that is based on the addition reaction of free radicals such as superoxide and hydroxyl radical to an EPR-silent spin trap, usually a nitrone compound, to form an EPRactive adduct. This radical adduct is more persistent than the parent radical and displays a characteristic EPR spectrum (Fig. 1).

Until recently, the only spin trap suitable for the detection of oxygen-centered radicals such as superoxide and hydroxyl radical was 5,5-dimethylpyrroline $\mathrm{N}$-oxide (DMPO). Nevertheless, one of the major drawbacks of using DMPO to detect superoxide is that the DMPO-superoxide adduct (DMPO-OOH) spontaneously decays to form DMPO-hydroxyl radical (DMPO-OH) [27]. Consequently the detection of superoxide using DMPO is rather indirect because it is based on the inhibition of the formation of DMPO-OH by SOD. Much effort has been dedicated during the last few years in the search and design of new trap agents that react faster with superoxide forming more persistent superoxide adducts. These two aspects of the spin trap methodology have been improved by the introduction of the phosphorylated DMPO-analog 5-diethoxyphosphoryl5-methyl-pyrroline N-oxide (DEPMPO) [28] and 2-ethoxycarbonyl-2-methyl-3,4-dihydro-2H-pyrrole-1-oxide (EMPO) [29] and its ${ }^{15} \mathrm{~N}$-labeled analog, $\left[{ }^{15} \mathrm{~N}\right]$-EMPO [30]. Figure 2 shows a time course study of the formation and decay of the<smiles>CCOOC1(C)CCC=[N+]1[O-]</smiles><smiles>[TeH]O[I-]</smiles>

DEPMPO<smiles>CCOC1(C)CCC(O)N1[O]</smiles>

DEPMPO-OOH

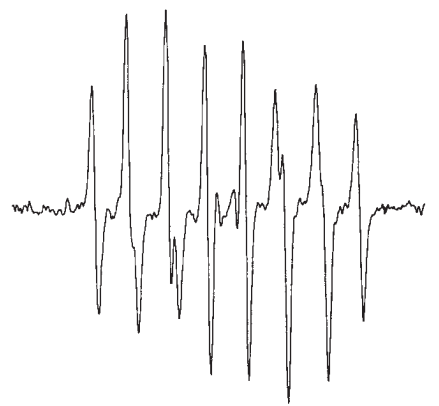

Figure 1. Representative example of a spin trapping reaction. Addition of superoxide to the DEPMPO, an EPR-silent compound, forms a persistent superoxide adduct DEPMPO-OOH which is EPR-active that displays a multi-line spectrum. 
<smiles>CC1(OC(F)(F)F)CCC(O)N1[O]</smiles>

A

B

$\mathrm{D}$

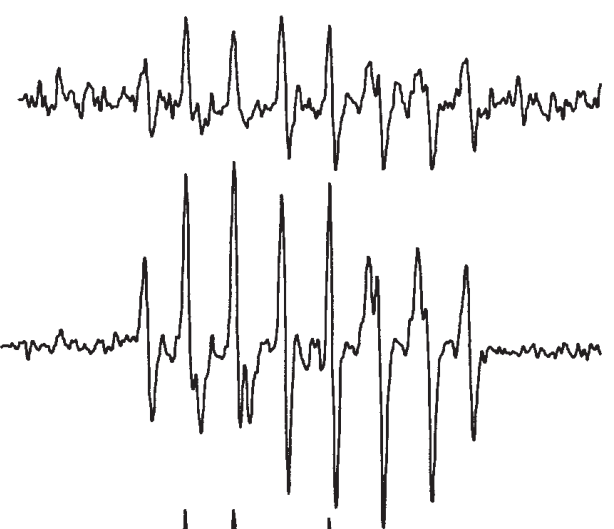

C

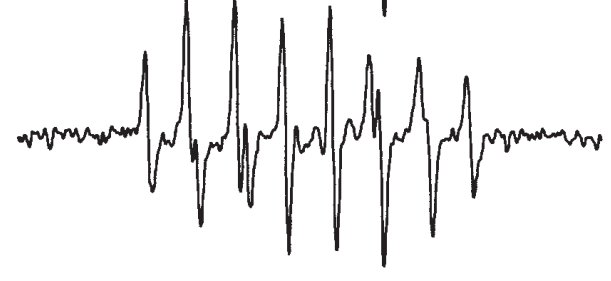

$20 \mathrm{G}$<smiles>CCOC(=O)C1(C)CCC(O)N1[O]</smiles>

D

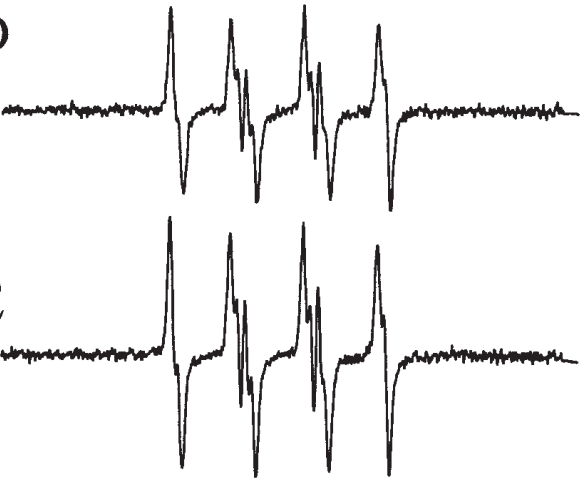

F

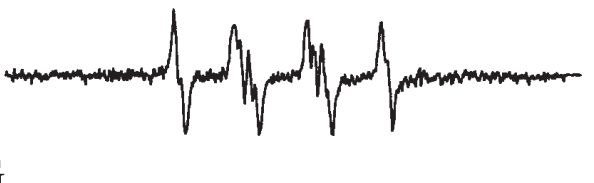

$10 \mathrm{G}$

Figure 2. Time dependent changes of the superoxide adducts of DEPMPO and EMPO. Incubation mixtures contained xanthine (1 mM), DTPA $(0.1 \mathrm{mM})$, xanthine oxidase $(0.4 \mathrm{U} / \mathrm{ml})$ and DEPMPO $(25 \mathrm{mM})$ for A,B,C or xanthine oxidase $(0.1 \mathrm{U} / \mathrm{ml})$ and EMPO $(25 \mathrm{mM})$ for $\mathbf{D}, \mathbf{E}, \mathbf{I}$. Samples were scanned after 5, 20 and $60 \mathrm{~min}$ of incubation, respectively. Traces D and G were obtained upon adding SOD (10 $\mu \mathrm{g} / \mathrm{ml})$.

DEPMPO and EMPO superoxide adducts, respectively. Both DEPMPO-OOH and EMPO-OOH are significantly more persistent than DMPO-OOH as indicated by their estimated time half lives of 14 and 8 min compared with 1 min for DMPO-OH [30]. Moreover, these adducts do not decay forming the corresponding hydroxyl adducts. This makes quantification more accurate. Sensitivity has been further improved by the substitution of the ${ }^{14} \mathrm{~N}(\mathrm{I}=1)$ by a ${ }^{15} \mathrm{~N}$ $(\mathrm{I}=1 / 2)$. As a result of the isotopic substitution, only a fourline pattern is detected for $\left[{ }^{15} \mathrm{~N}\right]-\mathrm{EMPO}-\mathrm{OOH}$ compared to the multi-line patters of $\left[{ }^{14} \mathrm{~N}\right]-\mathrm{EMPO}-\mathrm{OOH}$ and DEPMPO (Fig. 2). Consequently, the intensity of the $\left[{ }^{15} \mathrm{~N}\right]-\mathrm{EMPO}-$ $\mathrm{OOH}$ is higher than $\left[{ }^{14} \mathrm{~N}\right]-\mathrm{EMPO}-\mathrm{OOH}$ at the same rate of superoxide production (Fig. 3).

These new spin traps are powerful tools to examine the formation of superoxide in biological systems and in particular from NOS. Because of the lack of suitable methods for detecting superoxide, the formation of superoxide from NOS has been the subject of debate and controversy in literature.
Evidence for the formation of reactive oxygen species was previously presented in the literature. Formation of hydrogen peroxide by a calcium/calmodulin-dependent mechanism by the neuronal isoform of NOS was demonstrated under limited availability of $\mathrm{BH}_{4}$ [31]. Parallel EPR-studies demonstrated the formation of superoxide under limited availability of L-arginine [32]. However, no efforts were made to quantify superoxide and to examine whether superoxide was the only product formed by NOS [32]. These studies also failed to demonstrate the locus of oxygen activation by NOS. Because of the introduction of the loop gap technology that allows the EPR-analysis of exceedingly small amounts of samples and using DEPMPO, we presented definitive EPR spin trapping evidence for the generation of superoxide from eNOS and nNOS. We demonstrated that eNOS generates micromolar concentrations of superoxide by a calcium/calmodulin-dependent mechanism from the heme group at the oxygenase domain of the enzyme (Fig. 4) [33]. We also demonstrated that nNOS generates superoxide mainly from the oxygenase domain with 


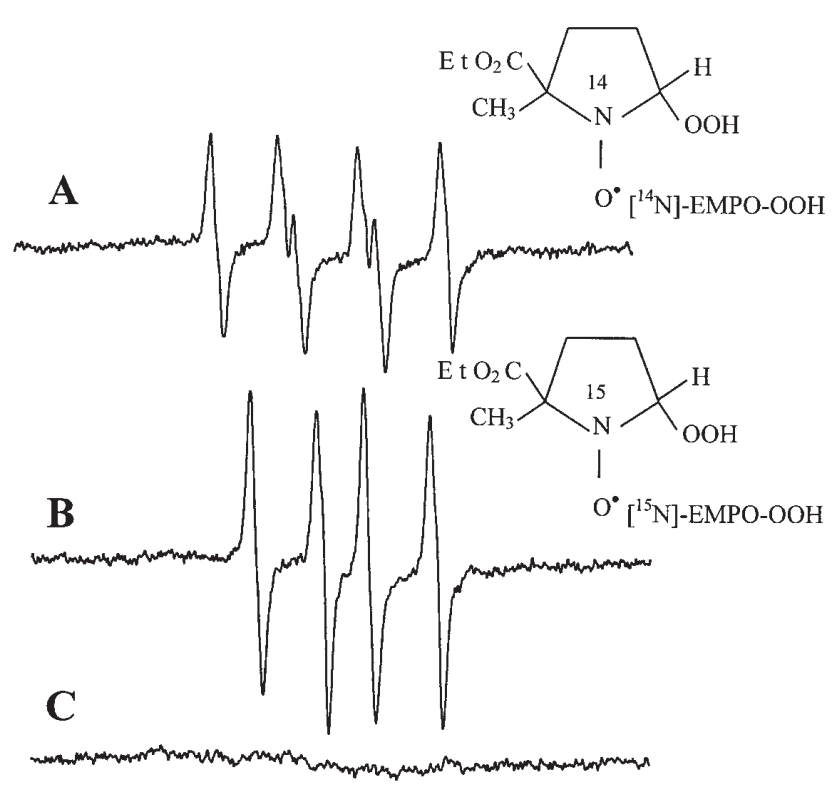

$20 \mathrm{G}$

Figure 3. Superoxide generation from nNOS detected using (A) $\left[{ }^{14} \mathrm{~N}\right]-E M P O$ and (B) $\left[{ }^{15} \mathrm{~N}\right]-E M P O$. Incubation mixtures contained nNOS $(1 \mu \mathrm{g})$, NADPH $(0.1 \mathrm{mM})$, calcium $(0.2 \mathrm{mM})$, calmodulin $(20 \mu \mathrm{g} / \mathrm{ml})$, DTPA $(0.1 \mathrm{mM})$ in Hepes buffer $(50 \mathrm{mM}, \mathrm{pH} 7.4)$ and (A) $\left[{ }^{14} \mathrm{~N}\right]-$ EMPO $(25 \mathrm{mM}) .(B)\left[{ }^{15} \mathrm{~N}\right]-$ EMPO $(25 \mathrm{mM})$. (C) Same as (A) but containing SOD $(10 \mu \mathrm{g} / \mathrm{ml})$.

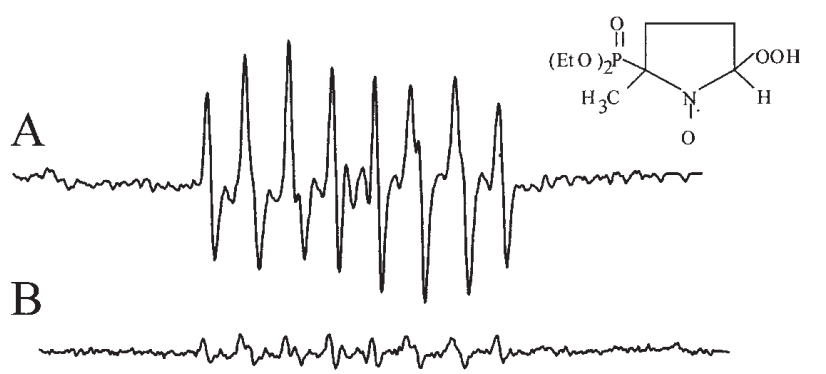

$\mathrm{C}$

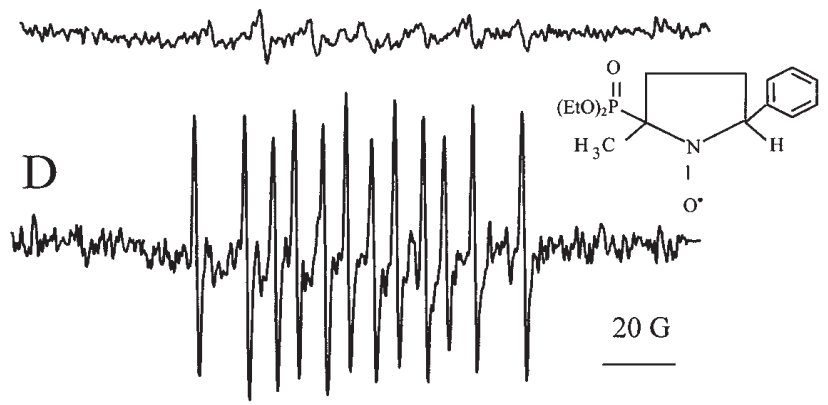

Figure 4. Calcium/calmodulin- dependent superoxide generation from eNOS. (A) Pterin-free eNOS (7 pmoles) was incubated with $\mathrm{Ca}^{2+}(0.2 \mathrm{mM})$, calmodulin $(20 \mu \mathrm{g} / \mathrm{ml})$, NADPH $(0.1 \mathrm{mM})$, DEPMPO (50 mM), DTPA (0.1 mM) in hepes buffer (50 mM, pH 7.4); (B) As (A) but without $\mathrm{Ca}^{2+}$ and calmodulin; (C) As (A) plus cyanide (1 mM); (D) As (A) after 15 min incubation with $1 \mathrm{mM}$ phenyldiazene. the reductase domain contributing to a minor extension of the total amount of superoxide generated by the enzyme [34]. In addition, DEPMPO showed to be very suitable for studying the mechanism of superoxide generation from NOS as it does not inhibit NOS activity and its sensitivity is sufficient to detect superoxide released from NOS. We have extended our studies to investigate the role of $\mathrm{BH}_{4}$ in oxygen activation by $\mathrm{nNOS}$ and the role of L-arginine analogs in superoxide generation by nNOS.

\section{Role of $\mathrm{BH}_{4}$ in superoxide generation from NOS}

Structural studies of eNOS and iNOS oxygenase domain dimer demonstrated that the pterin cofactor $\mathrm{BH}_{4}$ binds close to the heme group [35]. It was demonstrated that $\mathrm{BH}_{4}$ is held tightly bound to NOS through several hydrogen bonds, van der Waals forces and stacking interactions explaining the high affinity of the cofactor for all isoforms of NOS [35]. The role of $\mathrm{BH}_{4}$ in oxygen activation and in the catalytic cycle of NOS is poorly understood. We have further investigated the role of $\mathrm{BH}_{4}$ in the mechanism of oxygen activation by examining the role of $\mathrm{BH}_{4}$ in the generation of superoxide.

As shown in figure $5, \mathrm{BH}_{4}$ was very effective in decreasing the superoxide detected from pterin-free nNOS (Fig. 5, open squares). It was determined that the presence of L-arginine and $\mathrm{BH}_{4}$ further decreases the formation of superoxide (Fig. 5, close circles). Under these conditions NOS catalyzes the formation of L-citrulline at rates depending on $\mathrm{BH}_{4}$ concentrations (Fig. 5, close triangles). It was determined by $\mathrm{NADPH}$ consumption experiments that $\mathrm{BH}_{4}$ decreases the formation of superoxide by a mechanism that does not diminish NADPH consumption by the enzyme (not shown). This suggested that $\mathrm{BH}_{4}$ did not prevent the binding of oxygen to the heme at the oxygenase domain of nNOS and that $\mathrm{BH}_{4}$ inhibited the release of superoxide from nNOS. To examine whether this activity was unique to $\mathrm{BH}_{4}$, the role of $\mathrm{BH}_{4}$ analogs such as 7,8-dihydrobiopterin $\left(\mathrm{BH}_{2}\right)$ in the generation of superoxide by nNOS was investigated. 7,8$\mathrm{BH}_{2}$ did not inhibit formation of superoxide or NADPH consumption by nNOS (not shown). These results indicate that the activity of $\mathrm{BH}_{4}$ in controlling superoxide was not due only to occupation of $\mathrm{BH}_{4}$ binding site as $7,8-\mathrm{BH}_{2}$ also binds to the pterin binding site of NOS [36].

By analogy with P450 cytochrome enzymes, it has been proposed that the initial step in NOS activation is the reduction of the heme group [35,37]. Calcium/calmodulin-binding to NOS allows the reduction of the electron-transfer reaction from the reduced FMN to the heme group. Reduction of the heme allows the binding of molecular oxygen to form the first unstable intermediate of the catalytic cycle, the hemedioxygen complex (Scheme I). This intermediate can either release superoxide to regenerate the oxidized iron (III) form of the enzyme or accept a second electron to generate the 


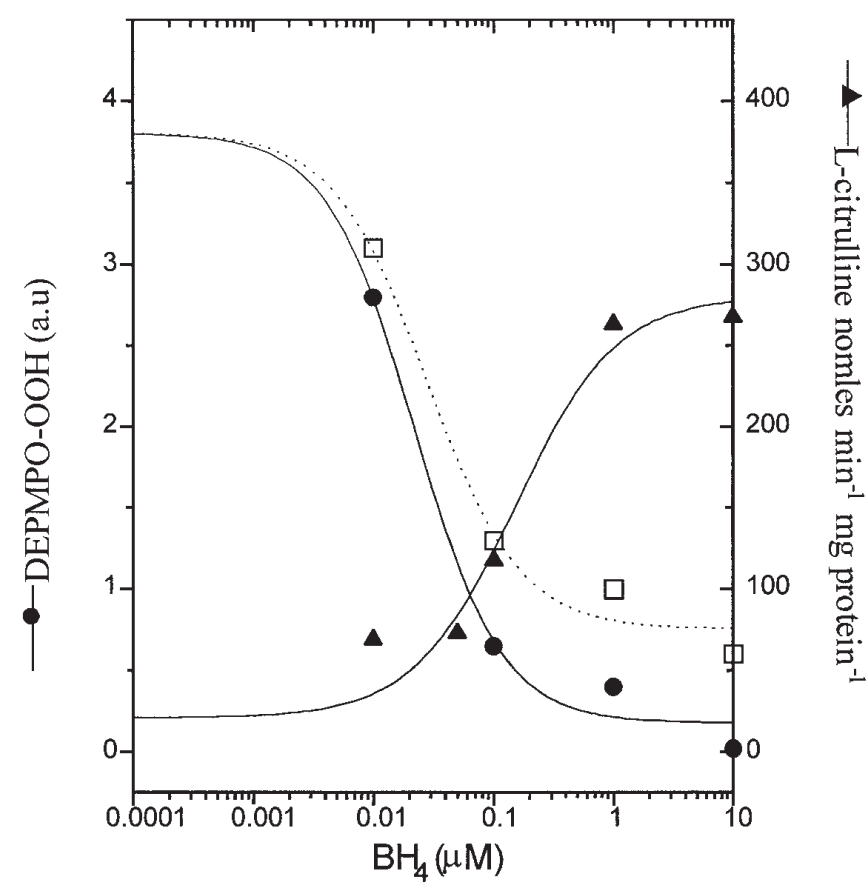

Figure 5. Tetrahydrobiopterin alone inhibits superoxide and in combination with L-arginine stimulates citrulline production from nNOS. Formation of DEPMPO-OOH was monitored after $1 \mathrm{~min}$ incubation of pterin-free nNOS $(1 \mu \mathrm{g})$ after the addition of calcium $(0.2 \mathrm{mM})$, calmodulin $(20 \mu \mathrm{g} / \mathrm{ml})$, NADPH $(0.1 \mathrm{mM})$, DEPMPO $(50 \mathrm{mM})$, DTPA $(0.1 \mathrm{mM})$ with $\mathrm{BH} 4$ alone $(\square)$ or in combination with L-arginine $(0.1 \mathrm{mM})(\mathbf{\bullet})$. Formation of ${ }^{14} \mathrm{C}$-L-Citrulline $(\boldsymbol{\Delta})$ was determined in parallel experiments using $0.1 \mathrm{mM}{ }^{14} \mathrm{C}$-L-arginine.

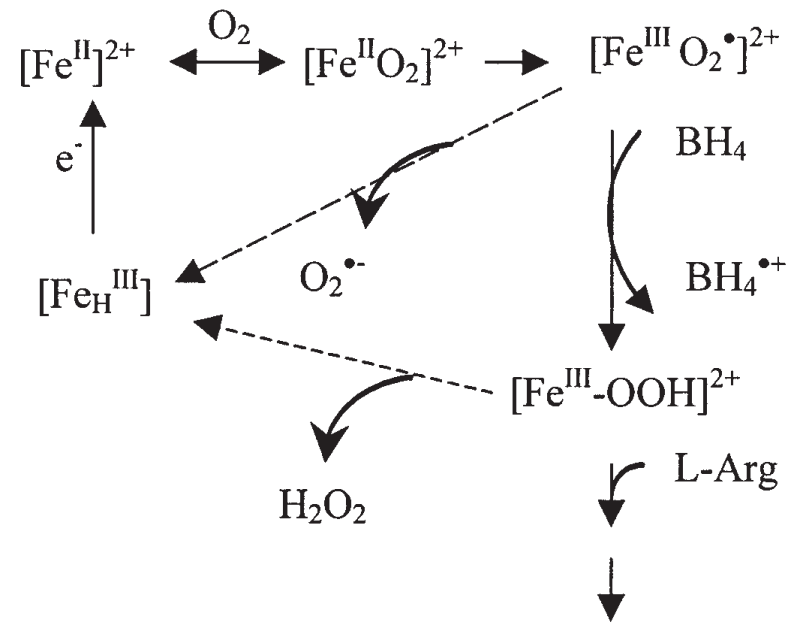

NOHA

Scheme I. Mechanism of BH4-dependent inhibition of superoxide release from $\mathrm{nNOS}$.

ANALUSIS, 2000, 28, No 6 heme-peroxo intermediate, which either decomposes to generate hydrogen peroxide and iron (III)-NOS or reacts with L-arginine to form N-hydroxy-L-arginine (Scheme I). It was suggested that $\mathrm{BH}_{4}$ reduces the ferrous-dioxygen complex, to form a $\mathrm{BH}_{4}$ cation radical $\left(\mathrm{BH}_{4}{ }^{+}\right)$and the heme-peroxo complex. Our results presented definitive evidence for this mechanism, demonstrating that only the fully reduced $\mathrm{BH}_{4}$ decreases the release of superoxide. In addition we demonstrated that activation of nNOS in the presence of saturating concentrations of $\mathrm{BH}_{4}$ inhibits the release of superoxide but does not diminish the formation of hydrogen peroxide by the enzyme. We conclude that $\mathrm{BH}_{4}$ critically controls the activation of oxygen by nNOS. In the absence of $\mathrm{BH}_{4}$ the ferrous-dioxygen complex is unstable releasing superoxide whereas in the presence of saturating concentrations of $\mathrm{BH}_{4}$ this complex is reduced to form the heme-peroxo intermediate that releases hydrogen peroxide. Under this condition superoxide is barely detected (Fig. 5).

Clinical studies have demonstrated that $\mathrm{BH}_{4}$ supplementation ameliorates vasoconstriction, which is associated with several conditions such as hypertension, hypercholesterolemia and diabetes. Our results suggest that $\mathrm{BH}_{4}$ controls vascular tone by inhibiting the release of superoxide from eNOS. As a consequence, $\mathrm{BH}_{4}$ enhances the bioavailability of nitric oxide and inhibits the formation of peroxynitrite in the vasculature.

\section{Conclusion}

The development of new superoxide traps has greatly improved the applicability of EPR spin trapping methodologies for the detection of superoxide in biological systems. In combination with the loop gap technology that allows the analysis of small sample volumes $(10-20 \mu l)$ the sensitivity of EPR technique has been further improved. Using DEPMPO it was presented for the first time, EPR evidence for the formation of hydroxyl radical from the inactivation of m-aconitase by superoxide [9]. Also, using DEPMPO we have unequivocally demonstrated the formation of superoxide from the oxygenase domain of both eNOS and nNOS $[33,34]$. All these studies have been critical in understanding the role of $\mathrm{BH}_{4}$ in oxygen activation and superoxide release from NOS. This demonstrates that the applicability of EPR techniques for the study of free radical pathophysiology has been greatly advanced and that the newly synthesized spin traps will help to elucidate the contribution of superoxide/NOS to endothelial dysfunction and neurodegenerative diseases.

\section{References}

1. Salvemini, D.; Wang, Z-Q.; Zweier, J.L.; Samouilov, A., Macarthur, H.; Misko, T.P.; Currie, M.G.; Cuzzocrea, S.; Sikorski, J.A.; Riley, D. P. Science 1999, 286, 304-306.

2. Estevéz, A.G.; Crow, J.P.; Sampson, J.B.; Reiter, C.; Zhuang, Y.; Richardson, G.J.; Tarpey, M.M.; Barbeito, L; Beckman, J. Science 1999, 286, 2498-2500. 
3. Konorev, E.A.; Kennedy, M.C.; Kalyanaraman, B. Arch. Biochem. Biophys. 1999, 368, 421-428.

4. Wallace, D.C. Science 1999, 283, 1482-1488.

5. Beckman, J.S.; Beckman, T.W.; Chen, J.; Marshall, P.M.; Freeman, B.A. Proc. Natl. Acad. Sci, USA 1990, 87, 16201624.

6. Fridovich, I. Ann. Rev. Biochem. 1975, 44, 147-159.

7. Huie, R.E.; Padmaja, S. Free Radical Res. Commun. 1993, 18 , 195-199.

8. Flint, D.H.; Tuminello, J.F.; Emptage, M. J. Biol. Chem. 1993, 268, 22369-22376.

9. Vásquez-Vivar, J.; Kalyanaraman, B.; Kennedy, M.C. J. Biol. Chem. 2000, 275, 14064-14069.

10. Gardner, P.R.; Nguyen, D-D.H.; White, C.W. Proc. Natl. Acad. Sci. USA 1994, 91, 12248-12252.

11. Chance, B.; Sies, H.; Boveris, A. Physiol. Rev. 1979, 59, 527605 .

12. Seifert, R.; Schultz, G. Rev. Physiol. Biochem. Pharmacol. 1991, 117, 1-338.

13. Vásquez-Vivar, J.; Hogg, N.; Martásek, P.; Karoui, H.; Tordo, P.; Pritchard, K.A. Jr.; Kalyanaraman, B. Free Rad. Res. 1999, 31, 607-617.

14. Shi, X.; Dong, Z.; Dalal, N.S.; Gannett, P.M. Biochim. Biophys. Acta 1994, 1226, 65-72.

15. Prictchard, K.A. Jr.; Groszek, L.; Smalley, D.M.; Sessa, W.C.; Wu, M.; Villalon, P.; Wolin, M.S.; Stemmerman, M.B. Circ. Res. 1995, 77, 510-518.

16. Ilan, Y.A.; Czapski, G.; Meisel, D. Biochim. Biophys. Acta 1976, 430, 209-224.

17. McCord, M.; Fridovich, I. J. Biol. Chem. 1969, 244, 60496055.

18. Klatt, P.; Schmidt, K.; Brunner, F.; Mayer, B. J. Biol. Chem. 1992, 267, 11374-1378

19. Chen, P.-F.; Tsai, A.-L.; Berka, V.; Wu, K.K. J. Biol. Chem. 1997, 6114-6118.

20. Kappock, T.J.; Caradonna, J.P. Chem Rev. 1996, 96, 26592656.

21. Vásquez-Vivar, J.; Martásek, P.; Hogg, N.; Karoui, H.; Masters, B.S.S.; Pritchard, K.A.Jr.; Kalyanaraman, B. Methods Enzymol. 1999, 301, 169-177.
22. Faulkner, K.; Fridovich, I. Free Radical Biol. Med. 1993, 15, 447-451.

23. Legg, K.D.; Hercules, D.M. J. Am. Chem. Soc. 1969, 91, 1902-1907.

24. Vásquez-Vivar, J.; Hogg, N.; Pritchard, K.A.Jr.; Martásek, P.; Kalyanaraman, B. FEBS Lett. 1997, 403, 127-130.

25. Tarpey, M.M.; White, R.; Suarez, E.; Richardson, G.; Radi, R.; Freeman, B.A. Circulation Res. 1999, 84, 1203-1211.

26. Benov, L.; Sztejnberg, L.; Fridovich I. Free Radical Biol. Med. 1998, 25, 826-831.

27. Finkelstein, E.; Rosen, G.M.; Rauckman, E.J. Molec. Pharmacol. 1982, 21, 262-265.

28. Frejaville, C.; Karoui, H.; Tuccio, B.; Le Moigne, F.; Culcasi, M.; Pietri, S.; Lauricella, R.; Tordo P. J. Med. Chem. 1995, 38, 258-265.

29. Olive, G.; Mercier, A.; Le Moigne, F.; Rockenbauer, A.; Tordo P. Free Radical Biol. Med. 2000, 28, 403-408.

30. Zhang, H.; Joseph, J.; Vásquez-Vivar, J.; Karoui, H.; Nsanzumuhire, C.; Martásek, P.; Tordo, P.; Kalyanaraman, B. FEBS Lett. 2000, 473, 58-62.

31. Heinzel, B.; Klatt, M.; Bohme, E.; Mayer, B. Biochem. J. 1992, 281, 627-630.

32. Pou, S.; Pou, W.S.; Bredt, D.S.; Snyder, S.H.; Rosen, G.M. J. Biol. Chem. 1992, 267, 24173-24176.

33. Vásquez-Vivar, J.; Kalyanaraman, B.; Martásek, P.; Hogg, N.; Masters, B.S.S.; Karoui, H.; Tordo, P.; Pritchard, K.A. Proc. Natl. Acad. Sci. USA 1998, 95, 9220-9225.

34. Vásquez-Vivar, J.; Hogg, N.; Martásek, P.; Karoui, H.; Pritchard, K.A. Jr.; Kalyanaraman, B. J. Biol. Chem. 1999, 274, 26736-26742.

35. Raman, C.S.; Partásek. P.; Masters, B.S.S. In The Porphyrin Handbook; Kadish, K.M.; Smith, K.M.; Guilard, Eds., Vol 4/biochemistry and binding: activation of small molecules, New York: Academic Press, 2000; pp 293-339.

36. Klatt, P.; Pfeiffer, S.; List, B.; Lehner, D.; Glatter, O.; Bachinger, P.; Werner, E.R.; Schmidt, K.; Mayer, B. J. Biol. Chem. 1996, 271, 7336-7342.

37. White, K.A.; Marletta, M.A. Biochemistry 1992, 31, 66276631. 